$100 \mathrm{mg}$. may be given at weekly intervals. The treatment may produce objective improvement in ischaemic necrosis and symptomatic benefit in patients with persistent cold feet, but has no effect on intermittent claudication.

Many patients with symptoms primarily referable to the skin will improve after sympathectomy, but the selection of suitable cases in the elderly grows more difficult with increasing age.

\section{Symptomatic Relief}

Elderly patients often sleep badly and are especially liable to be kept awake by the discomfort which arises from cold feet and cramps. They are often helped by a regular dose of a barbiturate, but it should be remembered that old people often react unusually to these drugs and may become dizzy and disoriented. Simpson (1954) finds methylpentynol ("oblivon," "somnesin ") in doses of $1 \mathrm{~g}$. a safe and useful hypnotic in the elderly.

There is a further group of patients who develop a painful redness of the feet of the type described by Lewis (1946) as erythralgia. These are best advised to avoid dependency of the limb and to sleep with the feet outside the bedclothes, as the burning sensation is worse when the feet are warm. Sympathectomy should be considered in this type of case. Some patients develop so-called rest pain, which resembles intermittent claudication although it occurs at rest. This usually demands the administration of analgesic drugs, and they are almost always necessary in cases with established gangrene. It is wise to begin with the simple analgesics such as aspirin and phenacetin before resorting to methadone ("physeptone") or methorphinan ("dromoran"). The morphine group of alkaloids, which cloud consciousness to a greater extent, are best held in reserve. Chlorpromazine ("largactil "), which has a calming effect and tends to distract attention from pain, may prove valuable, especially in disorientated patients.

\section{Treatment of Gangrene}

Areas of threatened gangrene should be treated by the methods already described which improve the circulation to the skin. Once necrotic areas have developed, antibiotics should be administered and the areas kept clean and dry and exposed to the air. Pain is usually severe and demands the administration of analgesics. Local application of heat must be avoided. The decision when and where to amputate is best made in consultation with a surgeon. Occasionally occlusion of a main artery leads to a red and tender foot, but usually to massive gangrene, and high amputation is necessary. Diabetics form a special group. As we have' seen, the typical lesion is in the smaller vessels and relatively conservative measures are desirable. Walker (1953) has reported good results in diabetic pre-gangrene and gangrene treated with oxytetracycline (" terramycin").

\section{Venous Thrombosis}

The elderly are more prone to venous thrombosis than are the young. They frequently have a general slowing of the circulation to the legs and they are more often confined to bed either permanently from general weakness, arthritis, or hemiplegia, or temporarily from conditions such as acute respiratory infections and bouts of heart failure. To diminish this liability to venous thrombosis, the elderly should be confined to bed for as short a time as possible, especially after operations or acute infections. If this is impossible, passive or preferably active exercises of the legs should be instituted, and any complaint of pain in the legs or an unexplained rise of temperature should be immediately investigated with the possibility of venous thrombosis in mind. In established cases the advantages and disadvantages of anticoagulant therapy in the elderly should be carefully weighed. If the patient is in hospital it will usually be considered advisable. Measures such as paravertebral block or ligation of the femoral vein may be advised by a surgeon.

\section{Conclusion}

Peripheral vascular disease in the elderly presents special problems. The very fact of survival to old age suggests an arterial system relatively free from degenerative processes. Where symptoms occur the progress of the disease is relatively slow. The obese should be put on a low-fat diet. Diabetes is a common predisposing condition and if present should be treated. Little can be done to help patients with intermittent claudication. Prophylaxis against gangrene is, however, possible and important. It is always wise to give advice to a younger relative as well as to the patient, because the memory for recent events in the elderly is usually poor. When gangrene has developed, pain is severe and badly tolerated, and if amputation is withheld analgesics should be given freely. Diabetic gangrene can usually be treated conservatively with rest and antibiotics. Consultation with a surgical colleague is always advisable.

\section{REFERENCES}

Betts, J. W. (1954). British Medical Journal, 1, 1360

Droller, H. (1953). Cardiologia, Basel, 22, 247.

Droller, H. (1953). Cardiologia, Basel, 22, 247. 15, 199.

Duguid J B (1954). Jancet, $1,891$.

Edwards, J. W. L. et al. (1952). British Medical Journal, 2, 808.

Edwards, J. W. L., et al. (1952), Brittsh

Gofman, J. W. (1951). In Biological and Medical Physics, vol. 2, edited

by J. H. Lawrence and J. G. Hamilton. Academic Press, New Yor Goodwin, J. F., and Kaplan, S. (1951). British Medlical Journal, 1, 1102. Hamilton, M., and Wilson, G. M. (1952). Quart. J. Med., 21, 169. Kountz, W. B. (1951). Thyrotd Function and its Possible Role in Vascular Degeneration. Thomas, Springfield, Illinois.

Lewis, T. (1946). Vascular Disorders of the Limbs, 2nd ed. Macmillan, London.

Lundbak, K. (1954). Lancet, 1, 377.

Semple, R. (1953). Ibid., 1, 1064.

Watson, R. G. (1954). Ibid., 1, 883.

Walker, $\mathrm{R}, \mathrm{G}(1953)$ Ibid., i, 521.

\section{ANTICOAGULANTS IN CORONARY DISEASE*}

BY

\section{A. RAE GILCHRIST, M.D., F.R.C.P., F.R.C.P.Ed.}

AND

JOHN A. TULLOCH, M.C., M.D., M.R.C.P.Ed.

(From the Department of Cardiology, Royal Infirmary, Edinburgh)

Before reviewing the use of anticoagulants in obliterative coronary disease, it is desirable first to consider briefly the pathological processes which result in myocardial infarction. Irregular thickening at the expense of the arterial lumen, and rigidity and tortuosity of the arteries, are the outward features of advancing atherosclerosis. Constriction of the channel, leading to a reduction in coronary blood flow, particularly if gradual and progressive, has important consequences. The most remarkable of these is the development of a collateral interarterial circulation, on which the future integrity of the muscle cells depends. As its coronaries become sclerotic the heart strikes a balance between the rate of narrowing and the development of anastomoses. Tissue anoxia appears to be the main stimulus for the development of interarterial anastomoses.

\section{Infarct Formation}

It is unfortunate that in clinical work the terms " coronary occlusion," "coronary thrombosis," and " myocardial infarction" continue to be used synonymously. They

* Read in the Section of Medicine at the Annual Meeting of the British Medical Association, Glasgow, 1954. 
are in fact distinct pathological entities and can occur independently (Ravin and Geever, 1946). Coronary atherosclerosis is their common denominator. For the classical clinical syndrome characterized by the acute onset of precordial pain of anginal type, with a greater or less degree of shock and followed by the early development of a variety of signs of tissue destruction, the term "acute myocardial infarction" should be reserved. This is the state of affairs in which as a general rule an infarct can be diagnosed with confidence, located with accuracy electrocardiographically, and treated effectively with anticoagulants.

The term " coronary occlusion" should be reserved for an obliteration of the arterial lumen at a site determined by a local advance in the atherosclerotic process in the intima of the artery. Sclerotic occlusions can apparently occur independently of acute thrombus formation. It is a more gradual process and does not necessarily result in the formation of a circumscribed infarct, even when a relatively large artery is blocked-a fact which illustrates the importance of an adequate collateral circulation through the myocardium. In a pathological sense coronary occlusions-and they are not infrequently multiple-are the usual basis of the production of angina pectoris (Blumgart et al., 1941).

Thrombosis of a coronary artery or a large branch is a common but not an invariable cause of an acute myocardial infarct. Tissue necrosis is the immediate result of acute and sustained ischaemia. Nevertheless, injection studies of the coronary circulation supplemented by careful dissections indicate that, if the obliterative arterial disease develops slowly enough, anastomotic channels gradually increase in number and may ultimately yield a supply of blood at sufficient pressure to provide a reasonably efficient reserve. In these circumstances an area of myocardium, which would otherwise perish, can survive despite acute thrombus formation. On the other hand, if a major artery is suddenly blocked by a local thrombus and the remainder of the coronary tree is comparatively healthy, or if for some unknown reason anastomoses have failed to develop, then a circumscribed infarct is the inevitable result (Ravin and Geever, 1946).

An infarct may form in the absence of a coronary thrombosis. Extreme narrowing of the arteries, a grossly inadequate collateral circulation, and excessive demands on the part of the myocardium may result in such an acute degree of coronary insufficiency that local ischaemia leads to asphyxial necrosis and even to infarct formation. It must then be assumed either that the amount of cardiac work performed was extreme and in response to some exceptionally severe and sustained demand, or that the local coronary supply was abruptly reduced to minimal amounts. Acute coronary insufficiency of this nature commonly results in a patchy subendocardial necrosis (Horn et al., 1950). In these circumstances the clinical signs of tissue destruction are slight and transient.

\section{Clinical Diagnosis of Infarction}

It can therefore be understood how varied are the consequences of coronary disease, and how important is the balance struck between obliterative processes on the one hand and compensatory collateral channels on the other. Angina pectoris, acute coronary insufficiency, and acute myocardial infarction are overlapping syndromes, often difficult to distinguish clinically, yet commonly observed in greater or less degree in the one individual as fairly distinctive episodes in the life history of this form of advancing arterial disease. In general the recognition of frank infarct formation depends more on the metabolic derangements which accompany tissue necrosis than on the duration and severity of the pain, dyspnoea, or syncope which may mark the onset of the attack. Fever, leucocytosis, elevated sedimentation rate, increased serum fibrinogen, and augmented excretion of urinary urobilinogen (Evans et al., 1952) are indications of the body's general reaction to myocardial necrosis. In these circumstances multiple lead electrocardio- grams repeated over the course of a week or two almost invariably reveal the site and extent of the area infarcted and its rate of healing.

\section{The Therapeutic Problem}

These pathological and clinical concepts imply that the fundamental problem in treatment is' the control of coronary atherosclerosis. The application of measures known to favour a regression of the intimal lesions or even procedures designed to prevent an advance in the obliterative process, together with the development of a reserve anastomotic circulation, would be major therapeutic achievements. Anticoagulants fall far short of these ideals.

Nevertheless, evidence is accumulating which indicates that an upset of the control of intravascular clotting commonly occurs after an acute myocardial infarction. It would be even more helpful to know if the increased coagulability of the blood observed in the early days of the illness (Ogura et al., 1946) antedates the acute infarction. Unfortunately, techniques for the estimation of the clotting tendency of blood are open to wide individual variation and the evidence from different laboratories is conflicting. Beaumont et al. (1953) concluded that hypercoagulability persisted up to forty-eight hours after the infarct was sustained, to be succeeded by a reduced clotting tendency for approximately the next ten to fourteen days. Thereafter a variable degree of hypercoagulability was usually maintained for a few weeks. Further information on this aspect of coronary disease is highly desirable, particularly from the point of view of the prevention of infarction, notably when premonitory anginal symptoms give a clue to its early occurrence.

Myocardial infarction is a disease of extremes: the mildest examples may pass undetected, and the severest attacks are commonly immediately fatal. The overall mortality rate of first attacks is not known. For the large intermediate group of average or more than average severity, as encountered in hospital practice, the illness is commonly punctuated by complications which add greatly to the gravity of the situation. If not immediately fatal, they usually prolong convalescence and subsequently shorten the total survival period. The mortality rate for hospital patients suffering from acute infarction averages $33 \%$ in this country during the first six weeks, but it varies appreciably in different localities. For example, a consecutive series of patients observed in the Edinburgh Royal Infirmary, and known to have sustained transmural damage in an acute form, had a mortality rate of $41 \%$ (Tulloch and Gilchrist, 1950).

In the first six weeks the main and commonly fatal complications of acute infarction are shock of moderate to severe degree (29\%), congestive heart failure (29\%), and thrombo-embolic episodes (28\%) (Gilchrist, 1952). There is no denying that in the early weeks the illness runs a treacherous and for the most part an unpredictable course. Even in the mildest cases a thrombo-embolic episode can cause disaster. One myocardial infarct may follow on another without the slightest warning, even within a few days of the original attack. Only in retrospect are there "good-risk" cases of acute myocardial infarction.

It is not yet known whether anticoagulants, restricted in use to the first four weeks, influence the ultimate prognosis, though the evidence indicates an increased survival rate for these first few weeks. By permitting a relatively larger number of individuals to survive the acute phase, some of whom might otherwise have been expected to die, it is possible that the group of patients receiving anticoagulants may experience in the year or two following the attack a higher mortality than the conservatively treated controls. We have as yet insufficient information to permit of firm conclusions on this aspect of anticoagulant treatment.

The ultimate prognosis is also far from satisfactory. Our hospital experience indicates that, for every 100 conservatively treated males, approximately 60 survive the first six weeks of the acute illness. At the end of one and a half 
years from the onset half are dead. Of the original 100 only 40 survive the fourth anniversary of the acute attack. These findings paint perhaps too gloomy a picture, but they are an example of the course followed in a hospital series.

An analysis of the causes of death amongst the 60 conservatively treated males surviving the first six weeks of hospital treatment indicates that a recurrence of the myocardial infarct accounts for 14 of the 20 deaths observed in the four-year "follow-up," in addition to which nine patients had non-fatal recurrences. It is clear that having survived one myocardial infarct the hospital patient is more likely to die from a further attack than from any other cause, and commonly within a year. That there is an urgent need for the prevention of recurrences is now obvious, but as yet it is too early to assume that continued long-term anticoagulant therapy reduces the dangers. Detailed and well-controlled studies are fully justified and deserve to be continued.

\section{Objects in Anticoagulant Therapy}

The objects in using anticoagulants are worth re-emphasizing. In the presence of an acute infarct these drugs may be employed (1) to prevent any extension or propagation of the original thrombus, if one be present ; (2) to prevent the formation of secondary thrombi, whether endocardial in site and underlying the infarct or in the peripheral veins of the leg or elsewhere-by this means the risk of the escape of clot into the general arterial or pulmonary circuits may be lessened and the frequency of frank embolic complications reduced; and (3) to promote the dissolution, absorption, or recanalization of the original or secondary thrombi-experimentally, as shown by Wright et al. (1952-3) and Jewell et al. (1954), there is much to support this contention.

If we apply these theoretical considerations to the clinical problems of coronary disease, it is reasonable to suppose that anticoagulants might prove helpful, not only in the treatment of acute infarction but in its prevention.

\section{Response to Anticoagulants}

The clinical history indicates that perhaps $30 \%$ of major cardiac infarcts are preceded by attacks of acute coronary insufficiency. Premonitory attacks of angina, often spontaneous, sometimes nocturnal, and commonly more severe and protracted than the usual effort pain, may recur in an irregular way over a period ranging from a few hours to a matter of a week or two before the major infarct is sustained. Under these difficult and treacherous conditions the encouraging results of Nichol et al. (1954) justify the prompt use of anticoagulants, with the hope of preventing the early development of acute myocardial damage. When unsuccessful, necropsy studies in these circumstances would be of particular value.

A claim can also be made for the long-term use of anticoagulants for the prevention of recurrences after one or more infarctions have been sustained. Careful and systematic supervision of comparative groups over a number of years is required before reliable conclusions can be drawn regarding the value of anticoagulants under these conditions. Our experience to date is encouraging, but it yet remains to be determined whether the long-continued use of an anticoagulant justifies the troubles and risks involved in this form of treatment (Nichol and Borg, 1950).

It must be appreciated that anticoagulant therapy is only one aspect of the care of the patient stricken with an acute infarct. Other measures-for instance, the provision of adequate rest, the treatment of shock, and the prevention of congestive heart failure-are of equal if not greater importance.

So many factors influence the immediate prognosis in cardiac infarction that the results of treatment are difficult to assess. The age of the patient, the sex, the frequency of previous attacks, the severity and duration of the initial shock, the occurrence of congestive heart failure, and the promptness with which treatment is applied are among the important factors influencing the immediate outcome.
Furthermore, in contrast to the assessment of many other remedies used solely for their curative properties, the appraisal of anticoagulants is rendered more difficult as reliance must be placed on their powers to prevent serious complications. No dramatic response follows their use, but their value is shown by a reduction in the anticipated death rate and by a diminution in the incidence of thrombotic complications.

In recent years confirmation of the earlier claims made for anticoagulants in acute infarction has come from many independent workers using adequate control groups. Some of these results are incorporated in Table I, from which

TABLE I.-Results Obtained in Recent Years by Various Workers Using Simultaneous Control and Treated Groups

\begin{tabular}{|c|c|c|c|c|c|c|}
\hline \multirow[b]{2}{*}{ Author } & \multicolumn{3}{|c|}{ Anticoagulant Group } & \multicolumn{3}{|c|}{ Control Group } \\
\hline & Cases & Deaths & $\begin{array}{l}\text { Mortal- } \\
\text { ity \% }\end{array}$ & Cases & Deaths & $\begin{array}{l}\text { Mortal- } \\
\text { ity \% }\end{array}$ \\
\hline Schilling (1950) & 60 & 10 & $16 \cdot 7$ & 60 & 24 & $40 \cdot 0$ \\
\hline $\begin{array}{l}\text { Tulloch and Gilchrist } \\
\text { (1950) } \\
\text { ashktoff et } \dddot{\text { al }} \text { (1952) }\end{array}$ & $\begin{array}{r}70 \\
142 \\
75\end{array}$ & $\begin{array}{l}16 \\
18 \\
19\end{array}$ & $\begin{array}{l}22.8 \\
12.7 \\
25.3\end{array}$ & $\begin{array}{r}84 \\
145 \\
125\end{array}$ & $\begin{array}{l}34 \\
38 \\
51\end{array}$ & $\begin{array}{l}40 \cdot 5 \\
26 \cdot 2\end{array}$ \\
\hline $\begin{array}{l}\text { Wright, Beck, and } \\
\text { Marple (1954) }\end{array}$ & 589 & 93 & $16 \cdot 0$ & 442 & 103 & 23.4 \\
\hline Total & 936 & 156 & 16.6 & 856 & 250 & $29 \cdot 2$ \\
\hline
\end{tabular}

The findings substantiate the earlier claims that anticoagulants are capable of halving the death rate in the first six weeks after acute myocardial infarction.

it is evident that in general the death rate over the first six weeks is halved amongst those receiving anticoagulant therapy.

Considering the relatively good prognosis of the mildest attacks of myocardial infarction, Russek and Zohman (1952) have doubted the necessity or desirability of using anticoagulants as a routine measure in all cases. However, the practical results obtained to date provide the best justification for using these drugs and far outweigh the theoretical criticisms and misapprehensions of Evans (1954).

Our experience with anticoagulants in the treatment of acute infarction now extends over the past seven years, and is summarized in Table II. Only the 1947-50 series of

TABLE II.-Analysis of Our Seven-year Experience of the Anticoagulant Treatment of 321 Consecutive Hospital Patients Suffering from Acute Myocardial Infarction

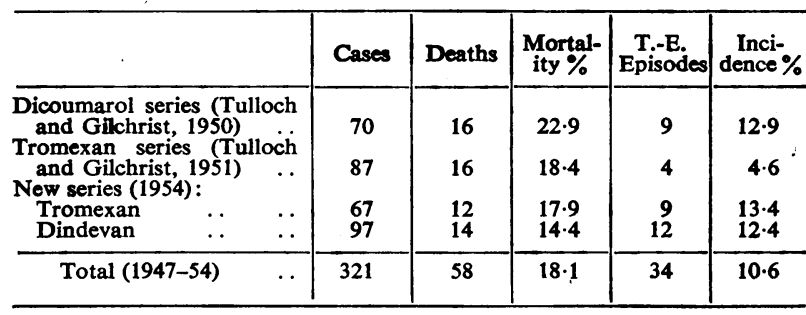

"The new series includes an additional 164 patients receiving either "tromexan " (ethyl biscoumacetate) or "dindevan" (phenylindanedione) incidence of thrombo-embolic episodes is now $10.6 \%$

dicoumarol-treated patients was compared with a simultaneous control group. It was then shown that the difference in mortality and in thrombo-embolic episodes was statistically significant, the death rate being halved in the treated group and the thrombotic complications being reduced to an even greater extent. With the passage of time, as shown in Table II, the mortality rate has fallen from $22.9 \%$ in the original treated series to $14.4 \%$ in our most recent experience. This reduction is largely attributable to the inclusion in recent years of a greater proportion of less acutely ill patients and to a less extent to greater experience in the handling of these drugs. We do not claim that the $41 \%$ mortality rate of the 1950 control group applies to our current hospital practice. If past experience is a guide, a mortality rate of approximately $28 \%$ might be anticipated in an Edinburgh control group at the present time. Similarly, the statistical analysis displayed in Table II does not 
warrant the claim that one anticoagulant is more or less efficient than another.

A consideration of the major causes of death in the first six weeks after an acute infarction has revealed that the overall reduction in mortality, observed when anticoagulants are in use, cannot be attributed solely to a decrease in frank thrombo-embolic deaths. It appears, for instance, that the early and efficient use of heparin followed by an oral anticoagulant may exert a favourable influence on the outcome of the shock syndrome (Gilchrist, 1952 ; Loudon et al. 1953). In a general way it is often true that one complication is soon followed by another. If survived, the severer grades of protracted cardiogenic shock predispose to congestive failure. Both clinical and pathological observations (Jordan et al., 1952) indicate that thrombo-embolic episodes are more common in those who develop these complications. It may be that by controlling the thrombotic tendency, early anticoagulant therapy may limit the size of the original infarct, save uninfarcted muscle, and thereby prevent an advance in the vicious circle of thrombosis, infarction, shock, and hypotension. Alternatively, it is possible that anticoagulants may exert effects other than those directly concerned with blood clotting, which may prove beneficial to these gravely ill patients. The available evidence clearly indicates that the prompt use of anticoagulants is to be encouraged if serious difficulties are to be avoided and the mortality rate reduced to $a^{a}$ minimum.

\section{Laboratory Control}

No anticoagulant is uniformly successful, despite as strict dosage control as laboratory methods permit. Notwithstanding daily prothrombin times, suitably maintained in the so-called therapeutic range by appropriate adjustment of the oral dosage from day to day, a minority of patients will develop thrombo-embolic complications. It is probable that such episodes are more likely to occur. if the use of heparin or other anticoagulant has been postponed even for 24 to 48 hours. The greater the interval elapsing between the production of the infarct and the development of a satisfactory control of the clotting tendency, the more probable is the formation of intraventricular clot and hence the subsequent detachment of emboli.

No anticoagulant is entirely free from the risks of haemorrhage, even despite strict laboratory supervision. Close watch must be kept for bleeding, the urinary tract being the most common source. We are fortunate in that the Edinburgh Royal Infirmary has a well-organized and efficient laboratory service. The daily dose is regulated according to the prothrombin time, and in actual practice serious haemorrhage is seldom encountered. Transfusion has been required on five occasions. Bleeding, perhaps no more than microscopic in amount, is encountered in $11 \%$ of patients, despite careful laboratory control and the exclusion of those patients known to suffer from anaemia, gross renal or hepatic disease, and ulceration of the gastro-intestinal tract. Advanced pregnancy, open wounds, raw surfaces, and recent surgical procedures indicate the exercise of great caution in the use of these drugs. If haemorrhage occurs, as it occasionally will in spite of every care, the anticoagulant in use should be withheld, vitamin $K_{1}$ prescribed, and if necessary a blood transfusion begun.

Of the various vitamin-K preparations carefully tested by Douglas and Brown (1952), including the water-soluble $\mathrm{K}$ analogue, only vitamin $\mathrm{K}_{1}$ was found to be a reliable and efficient antidote capable of blocking completely the action of therapeutic doses of dicoumarol and ethyl biscoumacetate. By its use excessive hypoprothrombinaemia could be corrected within a few hours. Toohey (1954), recommending smaller doses $\left(5-50 \mathrm{mg}\right.$.) of vitamin $\mathrm{K}_{1}$ than those commonly employed, emphasizes the need for caution when vitamin $K_{1}$ is administered in the presence of advanced hypoprothrombinaemia lest the risk of haemorrhage is replaced by the dangers of thrombosis. Prothrombin times repeated at intervals of a few hours can be of value in determining the necessity for further doses of the vitamin. If bleeding occurs, persists, and is profuse, there should be no hesitation in transfusing with fresh whole blood.

One consequence of undertaking the long-term treatment of a selected group of patients known to have sustained one or more myocardial infarcts is the recognition that the interval between successive prothrombin times may be lengthened with safety. As a general rule, after two to three weeks of daily blood samples it is justifiable to regulate the oral dosage by prothrombin estimations on alternate days. On beginning out-patient supervision the patient usually attends twice weekly for two to three weeks and, provided the oral dose is reasonably stable and the prothrombin times within the therapeutic range of two to two and a half times the control figure, once a week for the following two to three months. Later a blood sample once a fortnight may prove sufficient in the co-operative patient, who understands the significance of any unusual bleeding and who may be trusted with a supply of vitamin $\mathrm{K}_{1}$ for emergency use. From experience of the management of 227 out-patients receiving anticoagulants for a variety of conditions, Tulloch and Wright (1954) concluded that with reliable laboratory facilities long-term treatment was relatively safe and fully justified.

\section{Necropey Finding}

Support for the conclusions reached from clinical experience is also found in the analysis of the necropsy findings in 71 patients. Post-mortem examinations were made on 34 patients dying during the course of anticoagulant therapy, and on 37 patients from whom these drugs were withheld. Only a brief review of the major findings are mentioned here as more detailed studies are in progress.

The presence of recent acute infarction was demonstrated in all the cases. In the anticoagulant series ante-mortem mural thrombi were found in 13 instances $(38 \%)$, as compared with $19(51 \%)$ in the controls. In only $5(14.7 \%)$ of the treated group were peripheral or pulmonary thrombotic lesions recognized, as compared with $15(40.5 \%)$ in the control series. It is significant that thrombo-embolic lesions were therefore two and three-quarter times more common in the untreated than in the treated group. Many of these patients had multiple lesions involving the lungs, kidneys, or spleen, which had not been diagnosed clinically. The difference between the two groups is all the more striking when allowance is made for the fact that in our earlier experience the control of the prothrombin times was less intensive and less well maintained from day to day than is our current practice. Furthermore, the present analysis of thrombo-embolic lesions is confined to the pulmonary and general circulations without the inclusion of fresh cardiac damage in the form of reinfarction or extension of the original myocardial infarct responsible for the acute illness. Wright, Marple, and Beck (1954) noted that undiagnosed thrombo-embolic episodes were more frequently found at necropsy in the untreated than in the treated cases-a finding which emphasizes that comparison based on clinical studies underestimates the contrast between the two groups. Our pathological observations therefore support the contention of these authors that under the influence of anticoagulants the incidence of thromboembolic lesions is appreciably lessened.

\section{Summary}

The mechanism of the production of myocardial infarction is discussed in the light of newer knowledge concerning the arterial lesions of obliterative coronary disease on the one hand and the development of a subsidiary interarterial anastomotic circulation on the other.

In general the clinical recognition of frank infarct formation depends more on the metabolic upset which accompanies tissue destruction than on the duration of the pain, dyspnoea, or syncope, any one of which may mark the onset of the acute attack. 
A disease of extremes, acute myocardial infarction runs a treacherous and unpredictable course. There are only " good-risk" cases in retrospect.

Evidence continues to accumulate in support of the contention that anticoagulant drugs used early and efficiently, and continued for a minimum of four weeks under strict laboratory control, are capable of halving the death rate and reducing the incidence of thromboembolic episodes commonly observed during the first six weeks of the illness.

Necropsy experience substantiates the claim that anticoagulant therapy reduces the frequency of thromboembolic lesions.

The overall reduction in mortality cannot be attributed solely to the decrease in frank thrombo-embolic deaths. It appears that the severer grades of cardiogenic shock are favourably influenced by these drugs.

A claim can also be made for the prompt use of anticoagulants when a succession of attacks of acute coronary insufficiency suggests that myocardial infarction is imminent. There is also a justification for their use in selected patients on a long-term basis in the hope of preventing recurrences amongst those who have already sustained one or more myocardial infarcts.

No anticoagulant is uniformly successful. None is devoid of risk. Their successful use demands close clinical supervision supplemented by reliable laboratory facilities. Efficiently used, anticoagulants make a distinct contribution to the treatment of acute myocardial infarction.

\section{REFERENCES}

Reaumont, J. L., Chevalier, H., and Lenègre, J. (1953), Amer, Heart J.,

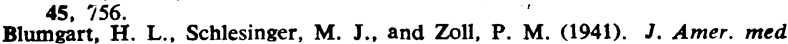
Ass., 116, 91 .

Douglas, A. S., and Brown, A. (1952). Brittsh Medical Journal, 1, 412.

Evans, J. M., Wood, O. H., and Brew, E. M. (1952). Circulation, 6, 925.

Evans, W. (1954). Proc. roy. Soc. Med., 47, 318.

(1952). British Medical Journal, 2, 351.

Horn, H., Field, L. E., Dack, S., and Master, A. M. (1950). Amer. Heart J., 40, 63.

Jewell, P. Pilkington, T., and Robinson, B. (1954). British Medical Journal, 1, 1013.

Jordan, R. A., Miller, R. D., Edwards, J. E, and Parker, R. L. (1952). Circulation, 6, 7

Loudon, I. S. L.., Pease, J. C., and Cooke, A. M., (1953). British Medical Journal, 1, 911

Nichol, E. S., and Borg, J. F. (1950). Circulation, 1, 1097.
Phillips, W. C., and Jenkins, V. E. (1954). Med. Clin. N. Amer. 38, 399.

Ogura, J. H., Fetter, N. R., Blankenhorn, M. A., and Glueck, H. I. (1946) J. clin. Invest., $25,586$.

Rashkoff, I. A., Schaefer, L. E., Maida, M. G., and Levy, H. (1952). J. Mt Sinat Hosp., 18, 350

Ravin A and Geever. E. F. (1946) Arch. intern. Med. 78, 125.

Ravin, A., and Geever, E. F. (1946). Arch. intern. Med., 78, 125.

Russek, H. I., and Zohman, B. L. (1952). Amer. Hear

Sching, F. (1950). Aner. med. Ass., 143, 785.

Tulloch, J. A. and Gilchrist, A. R. (1950). Ibid., 2, 965

Tulloch, J. A., and Gilchrist, A. R. (1951). Amer. Heart J., 42, 864.

- (1951). Amer. Heart J., 42, 864. 283

Wright, H. P., Kubik, M. M., and Hayden, M. (1952-3). Brit. J. Surg. 40,163 .

ight, I. S., Beck, D.

Marple C. D and Beck D. F (1954). Myocardial Infarction: Study of $i, 03 i$ Cases. Grune and Stratton, New York. (To be published.)

Scientific Research in British Universities 1953-54 (H.M.S.O., price 10s. net) is a massive 500-page paperbacked book issued by the Department for Scientific and Industrial Research in agreement with the Agricultural and the Medical Research Councils. The information in it has been collected direct from the heads of University Departments by the British Council. The Universities are taken alphabetically, and each department is listed, with the names of the head of the department and the permanent staff and a broad description of the research in progress during 1953-4. Under London University, the medical schools and institutes of the Postgraduate Medical Federation are separately scheduled. There is an index to the names of all research workers mentioned, and for the first time a detailed subject index.

\section{DISTRIBUTION OF MICROFILARIAE OF} O. VOLVULUS IN THE SKIN

ITS RELATION TO THE SKIN CHANGES AND TO EYE LESIONS AND BLINDNESS

BY

W. E. KERSHAW, V.R.D., M.D., D.T.M.\&H.

Lecturer in Medical Parasitology, Liverpool School of Tropical Medicine

B. O. L. DUKE, M.B., D.T.M.\&H.

Pathologist in Charge, Helminthiasis Research Scheme, Kumba

AND

\section{F. H. BUDDEN, M.B., D.O., D.T.M.\&H. Colonial Medical Service}

In the course of experiments undertaken in 1953 to investigate the quantitative aspects of the transference of Onchocerca volvulus from man to the vector, Simulium damnosum, in the British Cameroons, it became necessary to estimate the number of microfilariae in the skin which might be available for ingestion by the fly when taking up its blood meal. Skin snips taken from different parts of the body were weighed on a torsion balance, teased in saline on a slide, and the number of microfilariae issuing forth in a wet film were then counted. The results obtained in the British Cameroons had far-reaching implications concerning the clinical and epidemiological aspects of the infection, and, consequently, similar investigations were carried out in conjunction with ophthalmological studies in areas of Northern Nigeria where blindness is common. In 1954 these combined investigations were repeated in the British Cameroons.

Little attention seems to have been paid to the number of microfilariae to be found in a sample of skin, except that it seems to have been generally assumed that the number could be taken as a very rough measure of the intensity of the infection. The prevalent impression seems to have been that the microfilariae were of very uneven distribution, and that the number in adjacent portions of skin was extremely variable.

Buckley (1949), whilst in East Africa, made a quantitative study by counting the number of microfilariae issuing from skin snips which appeared on inspection to be of about the same size. The snips were taken from many corresponding sites on both sides of the trunk and limbs of a native of Kenya. Buckley concluded that the distribution was very uneven, was without pattern, and that because of the discrepancies the method he described could not be relied upon for a quantitative estimate of the degree of infection.

Blacklock (1926) and Mazzotti (1951) investigated the distribution in a qualitative manner by recording whether skin snips taken from different sites in different individuals were positive or negative. In Sierra Leone, Blacklock found microfilariae most commonly in the loins, next in the thighs, then in the scapular region, and rarely in the ankles. In Mexico, Mazzotti found them irregularly in the entire skin in the upper half of the body and pelvic girdle and rarely in the skin of the lower extremities.

\section{Material and Methods}

Samples of the skin were removed by inserting (almost horizontally) in the skin a very fine entomological pin 